\title{
Gastrointestinal Problems and Their Risk Factors Among Arba Minch Town Male Super League Football Club Players
}

\author{
Belay Silesh ${ }^{1^{*}} \quad$ Tiwabwork Tekalign $^{2} \quad$ Molla Doyou $^{3}$ \\ 1.College of natural and computational sciences, Dilla University Ethiopia \\ 2.Collage of natural and computational sciences, Arba Minch University Ethiopia \\ 3.College of Medicine and Health Sciences, Wolaita Sodo University Ethiopia
}

\begin{abstract}
Background-: Gastrointestinal symptoms experienced during competition are a major factor for reported reduced workload, session of activities, and withdrawal from many endurance competitions. So this study aimed was to assess the prevalence of exercise induced gastrointestinal problems and their risk factors among Arba Minch town male super league football club players

Objective-: The objective of this study was to assess the prevalence of exercise induced gastrointestinal problems and their risk factors among Arba Minch town male super league football club players.

Result; - A total of 31 subjects participated in the study with a response rate of $100 \%$. The prevalence of GI symptoms is found to be $45.2 \%$. Taking of NSAIDs frequently, doing exercise frequently and intensively, performing exercise on hot and humid environment and taking laxatives frequently identified as high risk factors. Unlikely, intake of tea/coffee for a long time and taking hypertonic fluid frequently are less risky to develop GI problem. According to this study prevalence exercise-induced gastrointestinal problems is high. Therefore, the concerned bodies shall intervene to tackle the problem.
\end{abstract}

Keywords: - Gastrointestinal problems, prevalence, risk factors, football players

DOI: $10.7176 / \mathrm{JMPB} / 69-04$

Publication date:March $31^{\text {st }} 2021$

\section{Introduction}

Soccer is a game played on a field between two teams of eleven players each with the object to propel a round ball into the opponent's goal by kicking or by hitting it with any part of the body except the hands and arms [1].

Exercise-related gastrointestinal symptoms are symptoms related to physiologic changes resulting from exercise [2]. Gastro-intestine (GI) is an important athletic organ because it is responsible for the delivery of water and nutrients during exercise [3].

The most frequent GI symptom caused by high-intensity exercise are heartburn, chest pain, bloating, belching, nausea, vomiting, abdominal cramp, frequent urge to defecate, diarrhea and constipation [4].

Frequently mode of exercise influences the occurrence and severity of gastro intestinal symptom (GIS) and sustained endurance exercise mediate increased permeability and damage in the GI tract [5,6]. More than $60 \%$ of endurance athletes report severe GIS during single-stage or multistage endurance competitions conducted in both hot and temperate ambient conditions [4].

Nearly, $4 \%-90 \%$ of endurance sport participants experience some adverse GI symptoms related to exercise including nausea, vomiting, abdominal cramps and the urge to have a bowel movement [7].

There is increased expression of GI disturbance symptomology in athletes after exercise of varying durations and intensity [8]. In Ethiopia both the prevalence and risk factors of exercise-induced GI problems had not been studied. So this study aimed to asses' prevalence of exercise-induced GI problems and their risk factors.

\begin{abstract}
Main text
Material and Methods

Study Area and period

The study was conducted in Arba Minch town, which is the capital city of Gamo zone,in south nation nationality region. It is $450 \mathrm{~km}$ away from Addis Ababa, the capital city of Ethiopia; and 273.57 kilo meter from Hawassa, the capital city of the region. This study was conducted from March 1-15, 2019.
\end{abstract}

Study design

Survey was employed.

Sample Size and Sampling Technique

All thirty- one (31) male Arba Minch town super league football players were taken and Convenience sampling technique was used. 


\section{Data Collection Procedures}

A questionnaire was first prepared in English and then translated into local language then back to English for checking consistency. The questionnaires have three parts: - socio-demographics characteristics, GI related problems and possible risk factors.

The data was collected by two data collectors and supervisors who hold BSc degree in sport science. Training was given for data collectors and supervisors. Pre-test was done on 5\% of the total sample size out of the study area

\section{Data Analysis}

After checking for completeness, missed value, unlikely response, coded and entered to Epi data version 3.5.1 then exported to SPSS version 22 and then bivariate analysis was done. Cross-tabulation was done to see the association between GI symptoms with the risk factors.

\section{Results}

\section{Socio-Demographic Characteristics}

A total of 31 football players participated in this study with a response rate of $100 \%$. Fifteen $(48.4 \%)$ of the participants were completed secondary school. Beyond Half of the participant 16 (51.6) \% of the participants were Gamo ethnicity (see Table 1).

\section{Prevalence of Gastrointestinal Problems}

The prevalence of gastrointestinal problems was $45.2 \%$ (see Figure 1).

\section{Risk Factors}

In the bivariate analysis, independent variables were cross-tabulated with the dependent variable after checking the assumption. Frequent use of NSAIDs, Performing exercise strenuously and frequently, Taking hypertonic drink, Doing exercise in hot and humid environment frequently, Laxatives use and Taking tea/coffee for a long time are variables cross-tabulated with gastrointestinal problem.

Participants who had use NSAIDs frequently were more likely to develop GI problems than their counterparts ( $85.7 \%$ versus $17.6 \%$ ), participants who had performing exercise strenuously and frequently were more likely to develop GI problems than who had not performing their exercise strenuously and frequently $(92.9 \%$ versus $35.3 \%)$

Those doing exercise in a hot and humid environment frequently were more likely to develop GI problem than their counterparts (85.7\% versus $41.2 \%)$.

Participants who had using of laxatives for a long time were more likely to develop GI problem than that of who had not use laxative for a long time $(85.7 \%$ versus $23.5 \%)$.

In other side participants who had taken hypertonic drinks frequently were less likely to develop GI problem than their counterparts (35.7\% versus $41.2 \%)$.

Participants who had taken tea/coffee for a long period of time were less likely to develop GI problems than who had not taking tea/coffee for a long period of time (35.7\% versus $76.5 \%)$ (See table 2$)$.

\section{Discussion}

The overall prevalence of gastrointestinal problems in this study was $45.2 \%$, similar with the study conducted in Netherland [9].

However, it is lower than other study conducted Netherland [10].The might be due to variation in sampling size, study design, fitness status of the participant.

Taking of non-steroidal anti-inflammatory drugs (NSAIDs) has significant association with GI problem; this study also showed that using NSAIDs frequently were more likely to develop GI problems $(85.7 \%)$ than those who had not taking.

Frequent use of NSAIDs leads to gastrointestinal side effects and more rarely cardiovascular and nephrotoxic events and also relevant alterations of the training adaptive processes in terms of sports performance and decreased tissue healing in terms of a lack of rehabilitation, hence increasing the risk of recurrent injury [11]. Additionally a study indicated that 1 in 5 athletes who are using NSAIDs reported that some NSAID-related side effects [12].

In this study those doing exercise strenuously and frequently were more likely to develop GI problem $(92.9 \%)$ than their counterparts. A self- report by $70 \%$ of athletes indicated that strenuous exercise and dehydration states resulted in GI symptoms [13].

Doing exercise in hot and humid environments is a risk factor. This study also showed that those doing exercise in hot and humid environments were more likely to develop GI problem than their counterparts $(85.7 \%)$. A study supports this finding that, athletes competing prolonged exercise events in the heat have 
reported symptoms such as, stomach cramps, intestinal cramps, diarrhea and gastrointestinal distress [13, 14].

A history of laxative abusing is a risk factor for the occurrence gastrointestinal problem. This study showed that using of laxative for long period of time were more likely to develop GI problems $(85.7 \%)$ than counterparts. Evidence indicated that using laxative causes abdominal discomfort by increasing the amount of stool [15].

In other side those consuming tea/ coffee for long period of time were less likely to develop GI problem (14.3\%). A study showed that withdrawing from caffeine for $0,2,12$ and 24 or 48 hours before ingesting caffeine $5 \mathrm{mg} / \mathrm{kg}$ did not alter metabolic responses to steady-state endurance exercise and cannot effect on GI [16].

Based on the finding of this study, a participant who had taken hypertonic fluids frequently were less likely to develop GI problem than who had not taken hypertonic fluid (35.7\%). Gastrointestinal stress is not observed until the concentration of carbohydrate is less than $8 \%$ [17].

\section{Conclusion}

According to this study prevalence of exercise-induced gastrointestinal problems is high. use of NSAIDs frequently, performing exercise strenuously and frequently, frequently doing exercise in a hot and humid environment, using of laxatives for long period of time are identified as risk factors to develop gastrointestinal problem. Unlikely, taking tea/coffee for a long period of time and taking hypertonic fluid frequently were a minor risk factor.

\section{Limitation of the study}

We are unable to generalize because of small sample size and there may be recall bias.

\section{List of Abbreviation}

BSc- Bachelor of Science

GI- Gastro Intestine

GIS- Gastro intestinal Symptoms

NSAIDs- Non-Steroidal Anti-Inflammatory Drugs

SPSS - Statistical package for social science

\section{Declarations}

\section{Ethics approval and consent to participant}

Ethical clearance and approval letter to conduct study was obtained from Arba Minch University ethical review board and a letter of cooperation was taken from the department of sport science. Written consent was taken from the participants before data collection and confidentiality of the information was ensured by coding. Participation was on a voluntary basis and responses were kept confidential.

\section{Consent for publication}

Not applicable.

\section{Availability of data and materials}

The data that support the findings of this study are available wit out restriction.

\section{Competing interests}

The authors declare that they have no competing interests.

\section{Funding}

The research was not funded.

\section{Authors' contributions}

Conceptualization: BS. Data curation: BS, MD \& TT. Formal analysis: BS, MD \&TT: Funding acquisition: BS. Methodology: BS, MD \&TT. Visualization: BS, MD \&TT: Writing - original draft: BS Writing - review \& editing: BS, MD \& TT.

\section{Acknowledgement}

We would like to express our deepest gratitude to data collectors and study participants without them our study could be stopped in the middle. 


\section{REFERENCES}

1. "Soccer." The Merriam-Webster.com Dictionary, Merriam-Webster Inc., https://www.merriamwebster.com/dictionary/soccer. Accessed 29 January 2020.

2. Ter Steege RW, Kolkman JJ. Review article the pathophysiology and management of gastrointestinal symptoms during physical exercise, and the role of splanchnic blood flow. Aliment Pharmacol Ther. $2012 ; 35(5): 516-28$. doi: 10.1111/j.1365-2036.2011.04980.x.

3. De Oliveira, E.P.; Burini, R. \& Jeukendrup, C. Gastrointestinal complaints during exercise: Prevalence, etiology, and nutritional recommendations. Sports Medicine; 2014; 44: S79-S85

4. Casey E, Mistry DJ, \& McKnight JM. Training room management of medical conditions: sports gastroenterology. Clinical Sports Medicine ;2005; 24:525-540

5. Costa R. J. S., Snipe R. M. J., Kitic, C. M., et.al . Systematic review: exercise-induced gastrointestinal syndrome-implications for health and intestinal disease. Alimentary Pharmacology \& Therapeutics 2017b; 32(S2): s498-265

6. Roberts, J., Suckling, C., Peedle, G., Murphy, J., Dawkins, T., \& Roberts, M. An Exploratory Investigation of Endotoxin Levels in Novice Long Distance Triathletes, and the Effects of a Multi-Strain Probiotic/Prebiotic, Antioxidant Intervention Nutrients;2016; 8(11): 733.

7. Wilson, P. B. Frequency of Chronic Gastrointestinal Distress in Runners: Validity and Reliability of a Retrospective Questionnaire. International Journal of Sport Nutrition and Exercise Metabolism, 2017: 1-21.

8. Haaf, ten, DSM., van der Worp, MP., Groenewoud, HM., et al Nutritional indicators for gastrointestinal symptoms in female runners: The "Marikenloop study." BMJ Open, 2014; 4:8, e005780-e005780.

9. TerSteege, RW F, Van Der Palen, J., \& Kolkman, JJ. (2008). Prevalence of gastrointestinal complaints in runners competing in a long-distance run: An internet based observational study in 1281 subjects. Scandinavian Journal of Gastroenterology, 2008; 43:12: 1477-1482

10. Peters HP., Bos M., \& Seebregts L. gastrointestinal symptoms in long-distance runners, cyclists, and triathletes: prevalence, medication, and etiology. Am J Gastroenterology; 1999; 94:1570-81.

11. Lilly K.F., Athletes, NSAID, coxibs, and the gastrointestinal tract. Current Sports Medicine Reports; 2010; 9:103-105.doi:10.1249/JSR.0b013e3181d405a9.

12. Suzic Lazic J., Dikic N., \& Radivojevic N. Dietary supplements and medications in elite sportpolypharmacy or real need? Scandinavian Journal of Medicine Science Sports; 2009;

13. De Oliveira EP. \& Burini RC. The impact of physical exercise on the gastrointestinal tract. Current Opinion Clinical Nutrition Metabolic Care. 2009; 12:533-8

14. Lambert, G. P. Intestinal barrier dysfunction, endotoxemia, and gastrointestinal symptoms: the "canary in the coal mine" during exercise-heat stress? Medicine and Sport Science; 2008; 53, 61-73.

15. Emma HB. \& Geoffrey IS., Complications of laxative abuse, Annual Review of Medicine;1999; 47(1):12734 DOI: 10.1146/annurev.med.47.1.127

16. Greer F, Friars D, \& Graham TE. Comparison of caffeine and theophylline ingestion: exercise metabolism and endurance. Journal Applied Physiology;2000; 89: 1837-44

17. Shi, X.; Horn, M.K.; Osterberg, K.L., et al. gastrointestinal discomfort during intermittent high-intensity exercise: Effect of carbohydrate-electrolyte beverage. International Journal of Sport Nutrition and Exercise Metabolism; 2004;14:673-683.

\section{List of Table}

Table 1: Socio-demographic characteristics of participants, Arba Minch town male super league football club players, 2019

\begin{tabular}{|l|l|l|l|}
\hline Characteristics & Category & Frequency(N) & Percent (\%) \\
\hline \multirow{4}{*}{ Educational status } & Secondary school & 15 & 48.4 \\
\cline { 2 - 4 } & Greater than or equal to diploma & 12 & 38.7 \\
\cline { 2 - 4 } & Primary school & 4 & 12.9 \\
\hline \multirow{4}{*}{ Ethnicity } & Gamo & 16 & 51.6 \\
\cline { 2 - 4 } & Wolita & 8 & 25.8 \\
\cline { 2 - 4 } & Amhara & 4 & 12.9 \\
\cline { 2 - 4 } & Others ${ }^{1}$ & 3 & 9.7 \\
\hline
\end{tabular}

Others $^{1}$ - Gurage, Benishangul, Kembata, Hadeya 
Table 2 Table 3: Cross tabulation of risk factors $(n=31)$

Variables

\begin{tabular}{lc}
\hline Use of NSAIDs frequently & No \\
& Yes \\
\cline { 1 - 1 } Performing exercise strenuously and frequently & No \\
& Yes \\
Hypertonic fluid intake & No \\
& Yes \\
\hline Frequently doing exercise in a hot and humid & No \\
environment & Yes \\
\hline Use of laxative for long period of time & No \\
& Yes \\
\hline Tea/coffee intake for long period of time & No \\
& Yes
\end{tabular}

\begin{tabular}{|c|c|c|c|c|}
\hline \multirow[t]{2}{*}{ Category } & \multicolumn{2}{|c|}{$\begin{array}{l}\text { Gastrointestinal } \\
\text { problems }\end{array}$} & \multirow[t]{2}{*}{$\mathbf{X}^{2}$} & \multirow[t]{2}{*}{$P$ value } \\
\hline & No (\%) & Yes $(\%)$ & & \\
\hline No & $14(82.4)$ & $3(17.6)$ & 11.648 & 0.01 \\
\hline Yes & $2(14.3)$ & $12(85.7)$ & & \\
\hline No & $11(64.7)$ & $6(35.3)$ & 8.433 & 0.04 \\
\hline Yes & $12(38.7)$ & $13(92.9)$ & & \\
\hline No & $10(58.8)$ & 7 (41.2) & 0.00 & 1.00 \\
\hline Yes & $9(64.3)$ & $5(35.7)$ & & \\
\hline No & $10(58.8)$ & $7(41.2)$ & 4.679 & 0.031 \\
\hline Yes & $2(14.3)$ & $12(85.7)$ & & \\
\hline No & $13(76.5)$ & $4(23.5)$ & 9.528 & 0.02 \\
\hline Yes & $2(14.3)$ & $12(85.7)$ & & \\
\hline No & $4(23.5)$ & $13(76.5)$ & 3.697 & 0.055 \\
\hline Yes & $9(64.3)$ & $5(35.7)$ & & \\
\hline
\end{tabular}

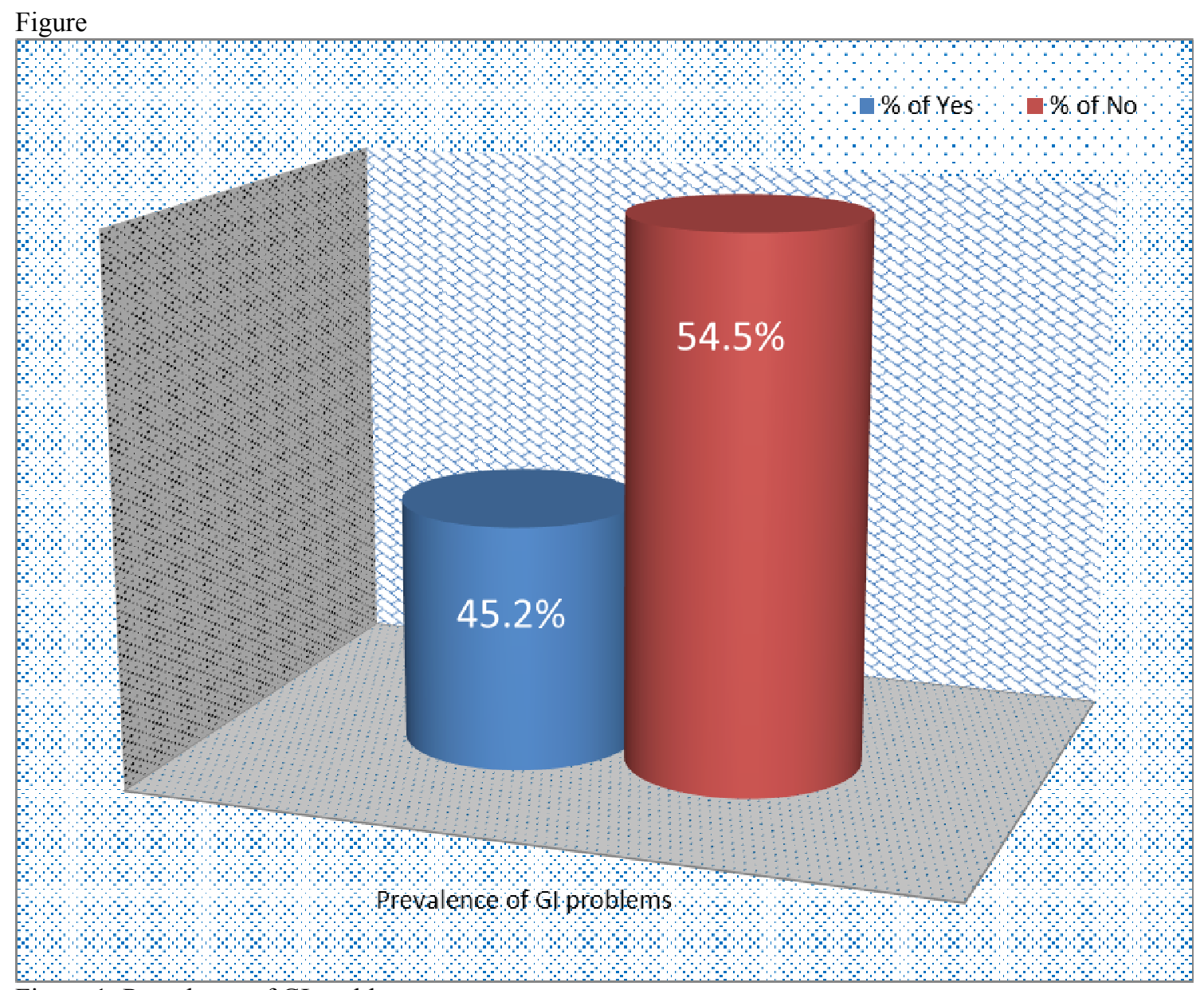

Figure 1: Prevalence of GI problems 